\title{
Interferential current sensory stimulation, through the neck skin, improves airway defense and oral nutrition intake in patients with dysphagia: a double-blind randomized controlled trial
}

\author{
This article was published in the following Dove Press journal: \\ Clinical Interventions in Aging \\ 7 November 2017 \\ Number of times this article has been viewed
}

\section{Keisuke Maeda ${ }^{1,2}$ \\ Takayuki Koga ${ }^{3}$ \\ Junji Akagi ${ }^{4}$}

'Department of Nutrition and Dysphagia Rehabilitation, Tamana Regional Health Medical Center, Kumamoto, ${ }^{2}$ Palliative Care Center, Aichi Medical University, Nagakute, ${ }^{3}$ Department of Swallowing and Nutritional Therapy, ${ }^{4}$ Department of Surgery, Tamana Regional Health Medical Center, Tamana, Tamana City, Kumamoto, Japan
Correspondence: Keisuke Maeda Palliative Care Center, Aichi Medical University, I-I Yazakokarimata, Nagakute, Aichi 480-I 195, Japan $\mathrm{Tel}+8|56| 6233 \mid \mathrm{I}$

Fax +8I 56I 786399

Email kskmaeda@aichi-med-u.ac.jp
Background: Neuromuscular electrical stimulation with muscle contraction, administered through the skin of the neck, improves a patient's swallowing ability. However, the beneficial effects of transcutaneous electrical sensory stimulation (TESS), without muscle contraction, are controversial. We investigated the effect of TESS, using interferential current, in patients undergoing dysphagia rehabilitation.

Methods: This double-blind, randomized controlled trial involved 43 patients who were prescribed in-hospital dysphagia rehabilitation for $\geq 3$ weeks. Patients were randomly assigned to the sensory stimulation (SS) or sham groups; all received usual rehabilitative care plus 2 weeks of SS or sham intervention. Outcome measures included cough latency times against a $1 \%$ citric acid mist, functional oral intake scale (FOIS) scores, and oral nutritional intake - each determined after the second and third week following treatment initiation.

Results: Mean patient age was $84.3 \pm 7.5$ years; $58 \%$ were women. The SS and sham groups had similar baseline characteristics. Changes in cough latency time at 2 weeks $(-14.1 \pm 14.0$ vs $-5.2 \pm 14.2 \mathrm{~s}, p=0.047)$ and oral nutrition intake at 3 weeks $(437 \pm 575 \mathrm{vs} 138 \pm 315 \mathrm{kcal} /$ day, $p=0.042$ ) improved more in the SS group than in the sham group. Changes in cough frequency and FOIS scores indicated better outcomes in the SS group, based on substantial effect sizes.

Conclusion: TESS, using interferential current through the neck, improved airway defense and nutrition in patients suffering from dysphagia. Further large-scale studies are needed to confirm the technique's effect on swallowing ability.

Keywords: transcutaneous electric nerve stimulation, deglutition disorders, rehabilitation, nutritional intake

\section{Introduction}

Dysphagia provoked by dysfunctional swallowing is a major cause of a poor quality of life and poor health, including the development of conditions such as malnutrition and aspiration pneumonia. ${ }^{1}$ Further, it may result from strokes, head and neck cancer, neurodegenerative diseases, and diverse conditions related to aging. ${ }^{1,2}$ Care for patients with dysphagia comprises both compensatory and rehabilitative approaches. ${ }^{3}$ The compensatory strategy includes food modifications and posture adjustments that minimize aspiration risk and encourage safe eating. On the other hand, the rehabilitative strategy is applied to improve dysphagia. Numerous rehabilitative strategies that consider both disease etiology and the patient's condition are available to treat these patients. Recently, systematic reviews have reported that transcutaneous neuromuscular 
electrical stimulation (NMES), which involves pulsed current stimulation through the neck to evoke muscle contractions, is effective for various types of dysphagia; ${ }^{4,5}$ the technique is widely applied in clinical practice. ${ }^{6}$

Sensory stimulation (SS) therapy, such as transcutaneous electrical SS (TESS), may be another potential strategy for treating dysphagia because activation of the peripheral sensory nerves in the larynx and the pharynx can contribute to protecting the airway from aspiration. ${ }^{7}$ In previous NMES device studies, swallowing improvements were reported in patients with dysphagia following the use of TESS involving low pulsed currents, without muscle contraction. ${ }^{8-10}$ Other SS methods are also effective at improving swallowing, including pharyngeal electrical stimulation, ${ }^{11}$ which directly stimulates the pharyngeal mucosa via pharyngeal electrodes, and chemical SS, using capsaicin. ${ }^{10}$ Therefore, the stimulation of the afferent nerves may be a key factor for dysphagia rehabilitation involving TESS, unlike the efferent nerve stimulation (NMES) that elicits muscle contraction and improves swallowing.

Some authors have reported that interferential current (IFC)-TESS might also be applied during dysphagia rehabilitation. ${ }^{12,13}$ IFC, which involves an electric beat carried on a carrier wave generated by sinuous currents of two different frequencies, has different conductivity characteristics than pulsed current. For example, IFC extends to deeper tissues and is more comfortable for the patient than pulsed current. ${ }^{14}$ Therefore, IFC-TESS is expected to stimulate nerves in the deep layers of the pharynx and larynx, without being uncomfortable. Although IFC-TESS enhances saliva production, ${ }^{15}$ shortens pharyngeal latency, ${ }^{13}$ and increases the swallowing frequency in healthy men, ${ }^{12}$ randomized controlled trials involving IFC-TESS have not been conducted in patients with dysphagia.

This study aimed to clarify whether IFC-TESS is effective in treating patients with dysphagia. In this study, we hypothesized that cough sensitivity might be improved by TESS because the stimulation does not evoke muscle contractions, but stimulates the sensory nerves inside the neck. The cough reflex in response to a foreign body in the airway plays an important role in respiratory defense, which is also important for safe swallowing and may be related to the prevention of aspiration pneumonia. Therefore, the primary outcome was an improved cough latency time.

\section{Materials and methods Design and participants}

A single-center, parallel-group, randomized, placebocontrolled study was conducted in our 150-bed hospital, which provides acute and post-acute medical care in a city with a population of approximately 100,000 . The study started in November 2015, with enrollment and follow-up ending in September and October 2016, respectively. Patients ( $\geq 65$ years) who were prescribed dysphagia rehabilitation for $>3$ weeks by their attending physicians were included in the study. Patients not providing informed consent or unable to remain still during the 15 -min stimulations were excluded. Additionally, patients who did not have a provoked cough on exposure to a citric acid mist for $<90$ s were excluded before initiating the intervention because the primary outcome was a measure of cough latency time. Patients who died during the study period were also excluded from the analysis (Figure 1).

Written informed consent was obtained from all patients or their legal guardians, and the study was approved by the ethics committee of Tamana Regional Health Medical Center (approval ID: TRHMC15-1-10), in accordance with the Declaration of Helsinki, and registered in the UMIN Clinical Trials Registry (SINE Stim Study ID: UMIN000019478). All authors had access to the study data and reviewed and approved the final manuscript.

\section{Device and sensory stimulation}

A portable device (Gentle Stim ${ }^{\circledR}$; J Craft, Osaka, Japan) that can generate an IFC with a beat frequency of $50 \mathrm{~Hz}$ was used to carry out TESS. A prototype of the device was used in previous studies, ${ }^{12,13,15}$ without any detectable adverse effects. This device was built to stimulate the nerves inside the neck through placement of two pairs of electrodes of different frequencies $(2,000$ and $2,050 \mathrm{~Hz})$ across the neck, as shown in Figure 2. The skin of the anterior neck was cleaned with a wet towel and, then, the electrodes were placed on the neck - the anterior electrodes at the edge of the thyroid cartilage and the posterior electrodes placed $4.0 \mathrm{~cm}$ from the ipsilateral electrode - along the mandible. The 15-min SS or sham interventions were undertaken twice per day (am and pm), 5 days per week for 2 weeks. The intensities of the SS and sham interventions were set at $3.0 \mathrm{~mA}$ (insufficient to produce muscle contractions) ${ }^{12}$ and $0.1 \mathrm{~mA}$, respectively. These procedures were not carried out during meal times or when other therapeutic interventions, such as dysphagia rehabilitation, physical training, and nursing care, were being performed. Because the study did not restrict any traditional rehabilitation or care procedures, participants in both groups received the usual treatment in addition to SS/sham stimulation.

\section{Sample-size calculation}

We used data from a previous study that reported cough latency times for patients with dysphagia to estimate our 


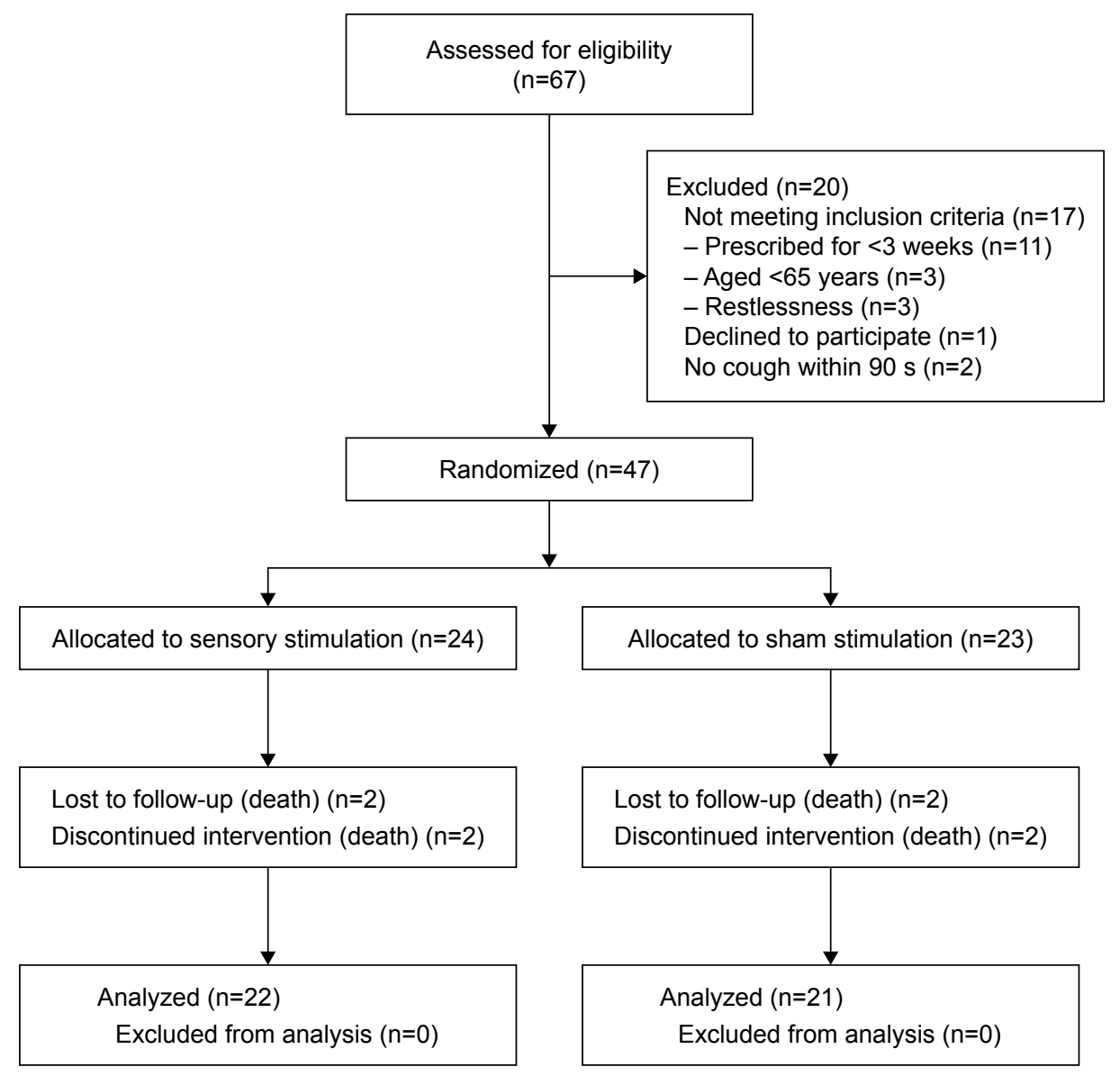

Figure I Study flow diagram.

Notes: Patients $(\mathrm{n}=47)$ were randomly divided into two groups. Ultimately, the two groups contained $2 \mathrm{I}$ and 22 patients who were included in the final analysis.

sample sizes. ${ }^{16}$ In that study, patients with silent aspiration (no reflexive cough) were assessed using videofluoroscopy, and demonstrated longer times to evoke the first cough after exposure to a mist of a $1 \%$ citric acid solution than

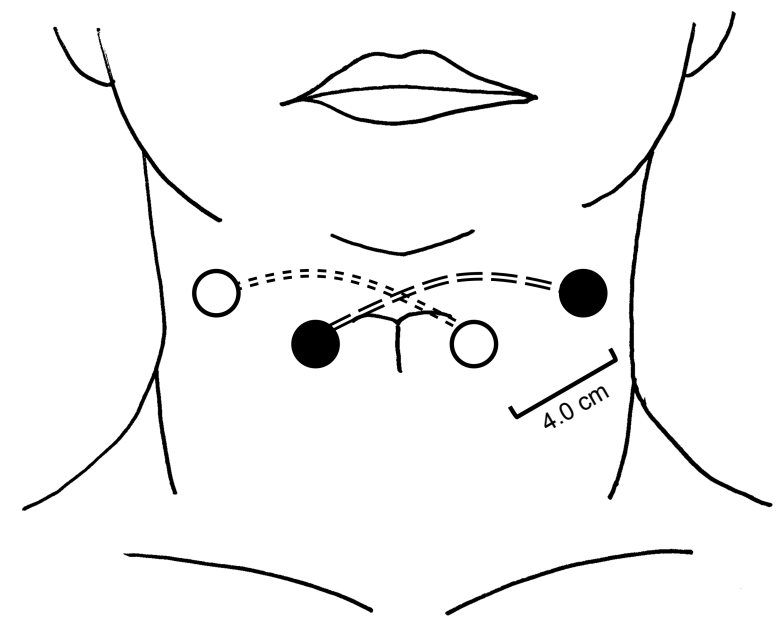

Figure 2 Electrode placement.

Note: Two different alternating currents $(2,000$ and $2,050 \mathrm{~Hz})$ are carried between pairs of electrodes, generating a 50-beat interferential current. did patients with apparent aspiration (having a cough). The standard deviation of the latency time for patients with dysphagia was $22.2 \mathrm{~s}$ and the time difference between patients with silent and apparent aspiration was 19.7 s. Assuming a similar difference between the SS and sham groups, at the end of the present study, 21 participants were expected to be required in each group to allow rejection of the null hypothesis, with a power $=0.8$ and an alpha error $=0.05$. Therefore, 47 participants were enrolled into the study, assuming a $10 \%$ dropout rate.

\section{Randomization, concealment, and blinding}

Each participant was randomized into either the SS or sham group (1:1 ratio) using a computer-generated sequence. Thereafter, all SS and sham interventions were administered by one person. The randomized sequence was concealed by an independent officer.

All of the participants, speech and language pathologists, nurses, dietitians, attending physicians, and physical therapists were also blinded to each patient's treatment group assignment. To blind the participants, all were informed 
that they might experience a sensation on their neck skin due to the attachment of the electrode tape, regardless of any electrical stimulation, and that they might experience diminished sensations because of their dysphagia. A similar method was used to blind participants in the previous report. ${ }^{17}$ The TESS instrument display was also obscured, both during SS or sham treatment, using an opaque cover to avoid the display being viewed by others. Furthermore, allocation information was concealed from the individual conducting the outcome assessments and statistical analyses until the analyses were complete. The primary outcomes were also concealed from all investigators, except the statistician, throughout the study period.

\section{Outcomes}

Cough latency time, following exposure to a mist of $1 \%$ citric acid in saline, ${ }^{16,18,19}$ was considered the primary outcome. A validated, handheld nebulizer (NE-U22; Omron, Kyoto, Japan $)^{16,18,19}$ was used to generate the mist. Cough latency times were measured, for each patient, upon study entry and at 2 and 3 weeks after entry. Cough latency was measured at approximately $2 \mathrm{pm}$ to minimize the influence of individual circadian conditions. During the test, each participant was asked to orally inhale the mist while sitting on a bed; the individual's nose was plugged to ensure oral breathing. The latency time (in seconds) from the time of exposure until the first cough was provoked ${ }^{16,18}$ and the 1-min cough frequency ${ }^{19}$ were recorded.

Each patient's intake of oral nutrition and their swallowing ability were considered secondary outcomes. Each participant's attending dietitian estimated the patient's oral energy intake upon study entry, and at 2 and 3 weeks after entry. The functional oral intake scale (FOIS) ${ }^{20}$ was used to assess oral intake. The FOIS is a 7-point (1-7) ordinal scale, where the highest value indicates normal swallowing ability and the lowest indicates the need for a feeding tube, without any oral intake.

\section{Measurements}

Each participant's characteristics, including age, sex, primary reason for admission, dysphagia etiology, and stroke history, were collected from their medical records. The patient's body mass index (BMI; body weight [kg] divided by height [m] squared) and the Mini-Nutritional Assessment Short Form (MNA-SF) ${ }^{21}$ were used as parameters of nutritional status. The MNA-SF is a validated scale, ranging from 0 to 14 , where scores of $0-7,8-11$, and 12-14 indicate malnutrition, risk of malnutrition, and normal nutritional status, respectively.
The Mini-Mental State Examination (MMSE), ${ }^{22}$ which represents global cognitive functioning (range, 0 [most severe] to 30 [normal]), was used as a parameter of cognitive function. Additionally, the Barthel Index (BI), ${ }^{23}$ which represents the activities of daily living (range, 0 [dependent] to 100 [independent]), was used as a measure of physical activity.

Dysphagia severity was assessed videofluorographically, using the Penetration Aspiration Scale (PAS), at baseline. This assessment involved each patient being asked to swallow approximately $3 \mathrm{~g}$ (a teaspoon) of barium-containing $3 \%$ gelatin as well as an extremely thick liquid during the videofluorography test; each aspect of the test was performed twice during each assessment. According to the International Dysphagia Diet Standardisation Initiative, ${ }^{24}$ the gelatin and liquid were both considered to represent texture level 4. Furthermore, we collected information pertaining to the duration of the physical and dysphagia rehabilitations that were provided during the intervention (2 weeks) and study (3 weeks) periods.

\section{Statistical analysis}

Quantitative variables are expressed as means \pm standard deviation. Differences between groups were analyzed using Welch's $t$-test. Categorical data are expressed as frequencies (percentages), with between-group differences being analyzed using Fisher's exact test. To document the intervention effect, the effect size (a measure of the relationship strength) was determined using $r$ for $t$-tests and phi for Fisher's exact tests. Effect size values of 0.10-0.20 are considered weak, $0.20-0.30$ mid-range, and $>0.30$ large; values $<0.10$ are considered negligible when measuring relationship strength. ${ }^{25}$ Changes from baseline were compared for each group, and were analyzed using Welch's $t$-test. All statistical analyses were conducted using SPSS v. 21 (IBM Japan, Tokyo, Japan); $p<0.05$ was considered to indicate statistical significance.

\section{Results}

Dysphagia rehabilitation was prescribed to 67 patients during the study period. Of these, 47 were enrolled in the study, after determining that they met the eligibility requirements (Figure 1). However, four patients (two in each group) were excluded because they died before the study's conclusion; thus, 43 patients were included in the final analysis. The baseline characteristics of the 43 participants (mean age, $84.3 \pm 7.5$ years; $58 \%$ were females) and their between-group comparisons are summarized in Tables 1 and 2. Dysphagia rehabilitation ( $\mathrm{n}=23,53.5 \%)$ was the most frequent primary reason for hospital admission, and most participants were 
Table I Baseline characteristics of the study participants

\begin{tabular}{|c|c|c|c|c|}
\hline & $\begin{array}{l}\text { Overall } \\
(n=43)\end{array}$ & $\begin{array}{l}\text { IFC sensory } \\
\text { stimulation } \\
(\mathrm{n}=22)\end{array}$ & $\begin{array}{l}\text { Sham } \\
\text { stimulation } \\
(n=2 I)\end{array}$ & $p$-value \\
\hline Age, years & $84.3 \pm 7.5$ & $82.7 \pm 8.0$ & $86.0 \pm 6.7$ & 0.155 \\
\hline Female, n (\%) & $25(58.1)$ & $12(54.5)$ & $13(6 \mid .9)$ & 0.760 \\
\hline Male, n (\%) & $18(41.9)$ & $10(45.5)$ & $8(38.1)$ & \\
\hline $\mathrm{BMI}, \mathrm{kg} / \mathrm{m}^{2}$ & $17.7 \pm 3.4$ & $17.3 \pm 3.0$ & $18.2 \pm 3.7$ & 0.430 \\
\hline MNA-SF score & $6.1 \pm 2.3$ & $5.9 \pm 2.5$ & $6.2 \pm 2.2$ & 0.647 \\
\hline Barthel Index score & $16.1 \pm 27.4$ & $19.6 \pm 32.7$ & $12.1 \pm 20.5$ & 0.368 \\
\hline MMSE score & $4.3 \pm 7.3$ & $5.6 \pm 8.9$ & $2.9 \pm 5.0$ & 0.216 \\
\hline Past stroke history & $21(48.8)$ & $9(40.9)$ & $12(57.1)$ & 0.366 \\
\hline \multicolumn{4}{|c|}{ Primary reason of admission } & 0.318 \\
\hline $\begin{array}{l}\text { Dysphagia } \\
\text { rehabilitation }\end{array}$ & $23(53.5)$ & $14(63.6)$ & $9(42.9)$ & \\
\hline $\begin{array}{l}\text { Aspiration } \\
\text { pneumonia }\end{array}$ & $13(30.2)$ & $6(27.3)$ & $7(33.3)$ & \\
\hline Others & $7(16.3)$ & $2(9.1)$ & $5(23.8)$ & \\
\hline
\end{tabular}

Note: Data presented as mean \pm standard deviation or $\mathrm{n}(\%)$.

Abbreviations: IFC, interferential current; BMI, body mass index; MNA-SF, MiniNutritional Assessment Short Form; MMSE, Mini-Mental State Examination.

malnourished, based on the mean BMI and MNA-SF values. Further, the mean BI and MMSE scores indicated that most were dependent and had severe cognitive impairment. There were no differences detected between the groups, based on their baseline characteristics (all, $p>0.05$ ). The mean cough latency time of $44.7 \mathrm{~s}$ suggests that many patients had silent aspiration at the beginning of the study.

Mean durations of rehabilitation training provided by specialists, including speech-language pathologists, trained nurses, and physical therapists, were similar between the groups. Dysphagia rehabilitation was undertaken for

Table 2 Baseline characteristics regarding cough reflex, swallowing, and nutritional intake

\begin{tabular}{|c|c|c|c|c|}
\hline & $\begin{array}{l}\text { Overall } \\
(n=43)\end{array}$ & $\begin{array}{l}\text { IFC sensory } \\
\text { stimulation } \\
(n=22)\end{array}$ & $\begin{array}{l}\text { Sham } \\
\text { stimulation } \\
(n=21)\end{array}$ & $p$-value \\
\hline Cough latency, s & $44.7 \pm 21.9$ & $44.0 \pm 22.2$ & $45.5 \pm 22.0$ & 0.822 \\
\hline $\begin{array}{l}\text { Cough frequency, } \\
\mathrm{n} / \mathrm{min}\end{array}$ & $1.4 \pm 1.4$ & $1.6 \pm 1.5$ & $1.1 \pm 1.2$ & 0.234 \\
\hline PAS score & $6.0 \pm 1.1$ & $6.2 \pm 1.0$ & $5.8 \pm 1.1$ & 0.259 \\
\hline FOIS score & $2.9 \pm 1.5$ & $2.7 \pm 1.5$ & $3.0 \pm 1.6$ & 0.563 \\
\hline Dysphagia etiology & & & & 0.666 \\
\hline Stroke & $22(5 \mid .2)$ & II (50.0) & II (52.4) & \\
\hline Post-acute disease & $9(20.9)$ & $6(27.3)$ & $3(14.3)$ & \\
\hline Cognitive disorder & $5(11.6)$ & $2(9.1)$ & $3(14.3)$ & \\
\hline Parkinson disease & $4(9.3)$ & I (4.5) & $3(14.3)$ & \\
\hline $\begin{array}{l}\text { Head and neck } \\
\text { disease }\end{array}$ & $3(7.0)$ & $2(9.1)$ & I (4.8) & \\
\hline $\begin{array}{l}\text { Nutritional oral } \\
\text { intake, kcal/day }\end{array}$ & $353 \pm 403$ & $306 \pm 452$ & $402 \pm 348$ & 0.438 \\
\hline
\end{tabular}

Note: Data presented as mean \pm standard deviation or $\mathrm{n}(\%)$.

Abbreviations: IFC, interferential current; PAS, Penetration Aspiration Scale; FOIS, functional oral intake scale.
$405 \pm 71 \mathrm{~min}$ in the SS group and for $366 \pm 173 \mathrm{~min}$ in the sham group during the first 2 weeks of the study ( $p=0.975$ ), and for $603 \pm 118 \mathrm{~min}$ and $612 \pm 56 \mathrm{~min}(p=0.748)$, respectively, during the study period. Physical rehabilitation was carried out for $395 \pm 256 \mathrm{~min}$ in the SS group and for $366 \pm 173 \mathrm{~min}$ in the sham group during the first 2 weeks $(p=0.669)$, and for $610 \pm 319 \mathrm{~min}$ and $571 \pm 217 \mathrm{~min}(p=0.647)$, respectively, during the study period.

Table 3 shows the outcomes comparison for the groups. After 2 weeks of IFC or sham stimulation, the mean cough latency time was longer in the sham group than in the SS group. Although not statistically significant ( $p=0.307$ ), the effect size appeared to be related to the group allocation $(r=0.32)$. Similar results were observed in the comparisons made at 3 weeks ( 1 week after ending the intervention). At this point, the cough frequencies, FOIS scores, and oral nutrition intakes also revealed better, but not statistically significant, outcomes in the SS group than in the sham group; a substantial effect size was observed. Additionally, we examined the changes from the baseline outcome parameters (Figure 3 ). The cough latency time at 3 weeks $(-14.1 \pm 14.0 \mathrm{~s}$ vs $-5.2 \pm 14.2 \mathrm{~s}, p=0.047)$ and the amount of oral intake at 2 weeks $(437 \pm 575 \mathrm{kcal} /$ day vs $138 \pm 315 \mathrm{kcal} /$ day, $p=0.042$ ) improved more in the SS group than in the sham group. Although the cough frequency and FOIS changes from baseline revealed better outcomes, with substantial effect sizes, these differences did not reach statistical significance.

There were no important harmful or unintended effects, such as vomiting, nausea, diarrhea, or pain or numbness of the throat in either the treatment or sham control groups. In addition, no patient developed aspiration pneumonia during the study period.

\section{Discussion}

This double-blind, randomized controlled trial involving older adults undergoing dysphagia rehabilitation was conducted to determine whether IFC-TESS provides patients with greater benefits than sham treatment. The study revealed two important results with regard to the effectiveness of IFC-TESS during dysphagia rehabilitation. First, the cough latency time, representing protection from aspiration, was restored to a greater degree in the SS group than in the sham group. Second, the amount of oral nutrition intake also showed a greater increase in the IFC-TESS group than in the sham group. Considering these points and the procedure's feasibility, IFC-TESS is a potentially feasible dysphagia rehabilitation approach. 
Table 3 Outcome comparisons between groups

\begin{tabular}{|c|c|c|c|c|c|c|c|c|}
\hline & \multicolumn{4}{|l|}{ At 2 weeks } & \multicolumn{4}{|l|}{ At 3 weeks } \\
\hline & IFC stimulation & Sham control & $p$-value & Effect size & IFC stimulation & Sham control & $p$-value & Effect size \\
\hline Cough latency, s & $32.6 \pm 21.2$ & $39.3 \pm 21.0$ & 0.307 & 0.32 & $30.0 \pm 20.8$ & $40.3 \pm 23.7$ & 0.136 & 0.46 \\
\hline Cough frequency, $\mathrm{n} / \mathrm{min}$ & $2.2 \pm 1.6$ & $1.4 \pm 1.1$ & 0.064 & 0.58 & $2.6 \pm 1.8$ & $1.7 \pm 1.6$ & 0.119 & 0.49 \\
\hline FOIS score & $3.8 \pm 1.3$ & $3.4 \pm 1.4$ & 0.306 & 0.32 & $3.8 \pm 1.3$ & $3.4 \pm I .4$ & 0.349 & 0.29 \\
\hline $\begin{array}{l}\text { Nutritional oral intake, } \\
\text { kcal/day }\end{array}$ & $743 \pm 582$ & $54 I \pm 45 I$ & 0.211 & 0.39 & $834 \pm 586$ & $625 \pm 491$ & 0.213 & 0.39 \\
\hline
\end{tabular}

Note: Data presented as mean \pm standard deviation.

Abbreviations: IFC, interferential current; FOIS, functional oral intake scale.

Changes in cough latency time, from baseline, improved more in the SS group than in the sham group. Although between-group comparisons of cough latency times at 2 and 3 weeks after intervention were not statistically significant, the differences showed significant effect sizes, confirming the value of evaluating these changes from the baseline. An insufficiently small sample size may have been responsible for these simple comparisons not demonstrating statistical significance. Improvements in cough latency times indicate that the protection of the airway against undesirable occurrences, such as aspiration, had increased. The cough latency time in the presence of a $1 \%$ citric acid mist is known to be longer in silent aspirators who do not cough, following
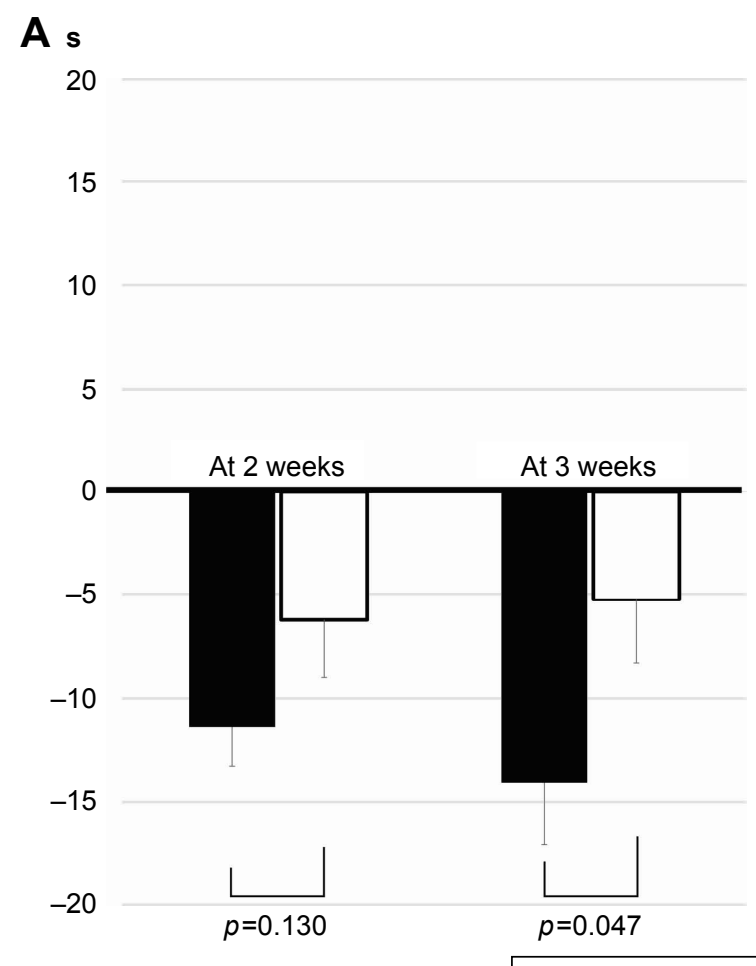

IFC stimulation aspiration, than in apparent aspirators who do cough. ${ }^{16}$ Additionally, some studies investigating TESS (pulsed current) effectiveness in dysphagia rehabilitation demonstrated improved PAS, ${ }^{8-10}$ which partially focuses on the coughing up of aspirated material, whereas another study failed to demonstrate kinetic motion improvements. ${ }^{26}$ Therefore, we believed that TESS may be useful for recovering this type of airway defense by increasing the sensitivity of the laryngeal and pharyngeal muscles.

Severe dysphagia is related to low oral nutrition intake ${ }^{3}$ and the subsequent malnutrition. ${ }^{27}$ However, in the present study, the amount of nutrition ingested by mouth increased more in the SS group than in the sham group. Given that silent

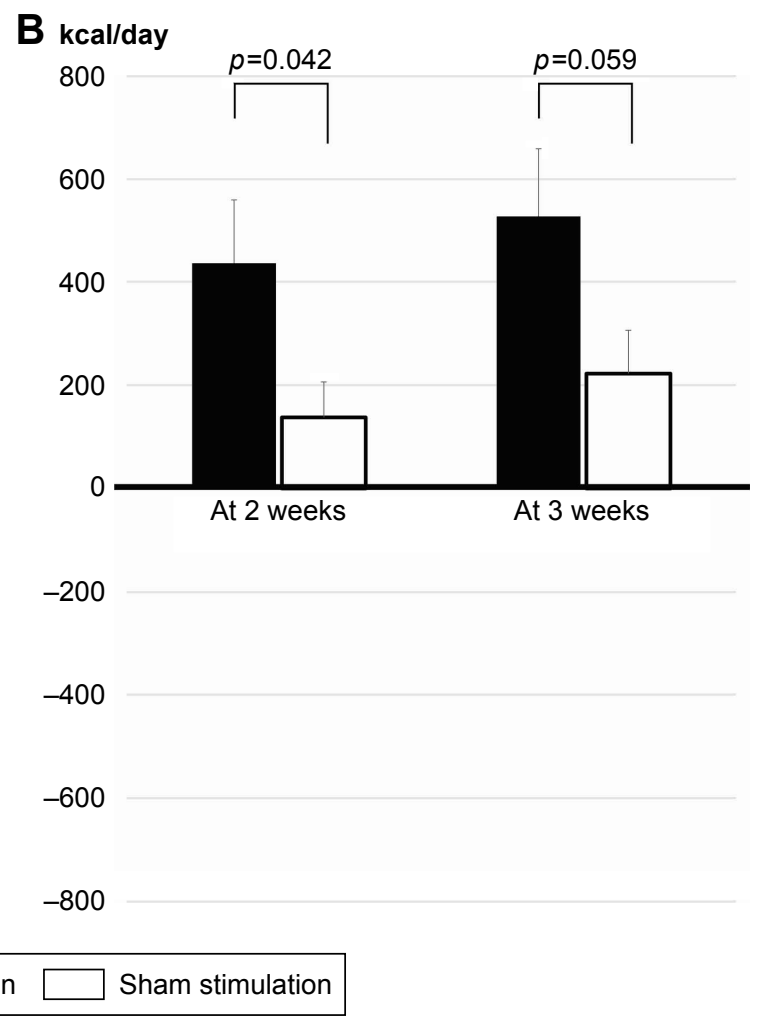

Figure 3 Changes from baseline in cough latency time and oral nutrition intake.

Notes: Interferential current (IFC) stimulation improves cough latency time (A) and oral nutrition intake (B), compared with sham stimulation, based on changes from baseline values. The closed and open bars represent the IFC sensory stimulation and sham stimulation groups, respectively. Error bars represent the standard errors of the mean. 
aspiration may be associated with poor nutritional status, ${ }^{28}$ the increased sensitivity of the airway attributed to IFCTESS treatment may help increase oral intake, as observed in this study. Moreover, improved swallowing efficiency may also be related to improvements in the sensations related to swallowing. Hiramatsu et $\mathrm{al}^{29}$ indicated that older adults are likely to experience swallowing fatigue during eating. Therefore, improved swallowing efficiency may lead to increased oral intake.

Comprehensive interventional strategies should be provided for patients with dysphagia, including dietary modifications, swallowing maneuvers, postural adjustments, muscle-strengthening exercises, and facilitatory techniques, based on individual assessments. ${ }^{3,30}$ Facilitatory techniques are ones that facilitate swallowing through sensory stimulation, such as thermal and gustatory stimulation. ${ }^{3}$ Therefore, TESS, which directly affects the afferent nerves of the larynx and the pharynx, should be considered a technique that facilitates swallowing, whereas NMES should be considered a strengthening exercise. To our knowledge, this is the first study to examine the effects of electrical stimulation on cough sensitivity and nutritional intake in patients with dysphagia. This is significant because the management of nutritional intake can prevent further decline in swallowing function. ${ }^{2}$ The study involved patients with severe cognitive disorders, according to their MMSE scores, who were unlikely to tolerate NMES stimulation because the associated muscle contractions would be uncomfortable, as evidenced by the fact that most NMES studies are not conducted in patients with severe cognitive disorders. However, such patients may undergo TESS treatment. Cognitive disorders are important aspects of dysphagia rehabilitation because they are associated with sarcopenia and sarcopenic dysphagia. ${ }^{2,31}$ Thus, facilitatory techniques, such as TESS, might be valuable for most patients with dysphagia, regardless of the specific etiology.

\section{Limitations}

The study has some limitations. First, we did not group the study participants according to their dysphagia etiology because the study was not designed to determine the etiologies that TESS might be most effective for treating. Second, we did not attempt to determine the optimal frequency and duration of TESS treatments. Conceivably, better intervention conditions may exist than those used in this study. Third, patients with dysphagia who were prescribed short courses of rehabilitation were excluded from the study. Thus, whether TESS could benefit such patients remains unclear.

\section{Conclusion}

IFC-TESS was demonstrated to produce favorable impacts on the cough sensitivity and nutritional status of patients with dysphagia. Future studies are needed to clarify the influence of disease etiology and different interventional methods on the outcomes of IFC-TESS treatment in the rehabilitation of patients with dysphagia.

\section{Acknowledgment}

This research received no specific grant from any funding agency in the public, commercial, or not-for-profit sectors.

\section{Disclosure}

The authors report no conflicts of interest in this work.

\section{References}

1. Clavé P, Shaker R. Dysphagia: current reality and scope of the problem. Nat Rev Gastroenterol Hepatol. 2015;12(5):259-270.

2. Maeda K, Takaki M, Akagi J. Decreased skeletal muscle mass and risk factors of sarcopenic dysphagia: a prospective observational cohort study. J Gerontol A Biol Sci Med Sci. 2017;72(9):1290-1294.

3. Wirth R, Dziewas R, Beck AM, et al. Oropharyngeal dysphagia in older persons - from pathophysiology to adequate intervention: a review and summary of an international expert meeting. Clin Interv Aging. 2016;11: 189-208.

4. Carnaby-Mann GD, Crary MA. Examining the evidence on neuromuscular electrical stimulation for swallowing: a meta-analysis. Arch Otolaryngol Head Neck Surg. 2007;133(6):564-571.

5. Clark H, Lazarus C, Arvedson J, Schooling T, Frymark T. Evidencebased systematic review: effects of neuromuscular electrical stimulation on swallowing and neural activation. Am J Speech Lang Pathol. 2009; 18(4):361-375.

6. Carnaby GD, Harenberg L. What is "usual care" in dysphagia rehabilitation: a survey of USA dysphagia practice patterns. Dysphagia. 2013;28(4):567-574.

7. Tsujimura T, Udemgba C, Inoue M, Canning BJ. Laryngeal and tracheal afferent nerve stimulation evokes swallowing in anaesthetized guinea pigs. $J$ Physiol. 2013;591(18):4667-4679.

8. Rofes L, Arreola V, López I, et al. Effect of surface sensory and motor electrical stimulation on chronic poststroke oropharyngeal dysfunction. Neurogastroenterol Motil. 2013;25(11):888-e701.

9. Zhang M, Tao T, Zhang ZB, et al. Effectiveness of neuromuscular electrical stimulation on patients with dysphagia with medullary infarction. Arch Phys Med Rehabil. 2016;97(3):355-362.

10. Ortega O, Rofes L, Martin A, Arreola V, López I, Clavé P. A comparative study between two sensory stimulation strategies after two weeks treatment on older patients with oropharyngeal dysphagia. Dysphagia. 2016;31(5):706-716.

11. Suntrup S, Teismann I, Wollbrink A, et al. Pharyngeal electrical stimulation can modulate swallowing in cortical processing and behavior - magnetoencephalographic evidence. Neuroimage. 2015; 104:117-124.

12. Furuta T, Takemura M, Tsujita J, Oku Y. Interferential electric stimulation applied to the neck increases swallowing frequency. Dysphagia. 2012;27(1):94-100.

13. Oku Y, Sugishita S, Imai T, et al. Effects of short term interferential current stimulation on swallowing reflex in dysphagic patients. Int $J$ Speech Lang Pathol Audiol. 2015;3(1):1-8.

14. Petrofsky J. The effect of the subcutaneous fat on the transfer of current through skin and into muscle. Med Eng Phys. 2008;30(9): $1168-1176$. 
15. Hasegawa Y, Sugahara K, Sano S, Sakuramoto A, Kishimoto H, Oku Y. Enhanced salivary secretion by interferential current stimulation in patients with dry mouth: a pilot study. Oral Surg Oral Med Oral Pathol Oral Radiol. 2016;121(5):481-489.

16. Lee JY, Kim DK, Seo KM, Kang SH. Usefulness of the simplified cough test in evaluating cough reflex sensitivity as a screening test for silent aspiration. Ann Rehabil Med. 2014;38(4):476-484.

17. Langmore SE, McCulloch TM, Krisciunas GP, et al. Efficacy of electrical stimulation and exercise for dysphagia in patients with head and neck cancer: a randomized clinical trial. Head Neck. 2016; 38(Suppl 1):E1221-E1231.

18. Sato M, Tohara H, Iida T, Wada S, Inoue M, Ueda K. Simplified cough test for screening silent aspiration. Arch Phys Med Rehabil. 2012; 93(11):1982-1986.

19. Wakasugi $Y$, Tohara H, Hattori F, et al. Screening test for silent aspiration at the bedside. Dysphagia. 2008;23(4):364-370.

20. Crary MA, Mann GD, Groher ME. Initial psychometric assessment of a functional oral intake scale for dysphagia in stroke patients. Arch Phys Med Rehabil. 2005;86(8):1516-1520.

21. Rubenstein LZ, Harker JO, Salvà A, Guigoz Y, Vellas B. Screening for undernutrition in geriatric practice: developing the short-form mini-nutritional assessment (MNA-SF). J Gerontol A Biol Sci Med Sci. 2001;56(6):M366-M372.

22. Folstein MF, Robins LN, Helzer JE. The mini-mental state examination. Arch Gen Psychiatry. 1983;40(7):812.

23. Mahoney FI, Barthel DW. Functional evaluation: the Barthel Index. Md State Med J. 1965;14:61-65.
24. Cichero JA, Lam P, Steele CM, et al. Development of international terminology and definitions for texture-modified foods and thickened fluids used in dysphagia management: the IDDSI framework. Dysphagia. 2017;32(2):293-314.

25. Cohen J. A power primer. Psychol Bull. 1992;112(1):155-159.

26. Park JW, Kim Y, Oh JC, Lee HJ. Effortful swallowing training combined with electrical stimulation in post-stroke dysphagia: a randomized controlled study. Dysphagia. 2012;27(4):521-527.

27. Tamura BK, Bell CL, Masaki KH, Amella EJ. Factors associated with weight loss, low BMI, and malnutrition among nursing home patients: a systematic review of the literature. J Am Med Dir Assoc. 2013;14(9): 649-655.

28. Sakai K, Hirano H, Watanabe Y, et al. An examination of factors related to aspiration and silent aspiration in older adults requiring long-term care in rural Japan. J Oral Rehabil. 2016;43(2):103-110.

29. Hiramatsu T, Kataoka H, Osaki M, Hagino H. Effect of aging on oral and swallowing function after meal consumption. Clin Interv Aging. 2015;10:229-235.

30. Maeda K, Shamoto H, Wakabayashi H, Enomoto J, Takeichi M, Koyama T. Reliability and validity of a simplified comprehensive assessment tool for feeding support: kuchi-kara taberu index. $J \mathrm{Am}$ Geriatr Soc. 2016;64(12):e248-e252.

31. Maeda K, Akagi J. Cognitive impairment is independently associated with definitive and possible sarcopenia in hospitalized older adults: the prevalence and impact of comorbidities. Geriatr Gerontol Int. 2017; 17(7):1048-1056.
Clinical Interventions in Aging

\section{Publish your work in this journal}

Clinical Interventions in Aging is an international, peer-reviewed journal focusing on evidence-based reports on the value or lack thereof of treatments intended to prevent or delay the onset of maladaptive correlates of aging in human beings. This journal is indexed on PubMed Central, MedLine,

\section{Dovepress}

CAS, Scopus and the Elsevier Bibliographic databases. The manuscript management system is completely online and includes a very quick and fair peer-review system, which is all easy to use. Visit http://www.dovepress. com/testimonials.php to read real quotes from published authors. 